\title{
Fibrose cardíaca associada à intoxicação por Amorimia septentrionalis em bovinos ${ }^{1}$
}

\author{
Samuel S.C. Albuquerque ${ }^{2}$, Brena P. Rocha², Valdir M. Almeida² , Juceli S. Oliveira ${ }^{3}$, \\ Franklin Riet-Correa ${ }^{4}$, Stephen T. Lee ${ }^{5}$, Joaquim Evêncio Neto ${ }^{6}$ e Fábio S. Mendonça ${ }^{6 *}$
}

\begin{abstract}
Albuquerque S.S.C., Rocha B.P., Almeida V.M., Oliveira J.S., Riet-Correa F., Lee S.T., Evêncio Neto J. \& Mendonça F.S. 2014. [Cardiac fibrosis associated to the poisoning by Amorimia septentrionalis in cattle.] Fibrose cardíaca associada à intoxicação por Amorimia septentrionalis em bovinos. Pesquisa Veterinária Brasileira 34(5):433-437. Universidade Federal Rural de Pernambuco, Rua Dom Manoel de Medeiros s/n, Dois Irmãos, Recife, PE 52171-900, Brazil. E-mail: fabio.mendonca@pq.cnpq.br

Amorimia (Mascagnia) septentrionalis contains sodium monofluoracetate and when consumed by ruminants cause outbreaks of sudden death. This study aimed to describe the epidemiology, clinical and pathological signs of outbreaks of sudden deaths in cattle caused by $A$. septentrionalis in the states of Pernambuco and Paraíba. For this, technical visits where made on various properties in the regions of Médio Capibaribe/PE and Itabaiana/PB. Eight cattle were necropsied. Tissues were collected from abdominal and thoracic cavities, besides brain and spinal cord. The clinical changes consisted in apathy, prolonged sternal recumbency, reluctance to move, fatigue, tachypnea, tachycardia and positive venous pulse. The animals that were forced to move showed instability, muscular tremors and then a single fall followed by vocalizations, paddling and death in 5-7 minutes. Macroscopic changes consisted in pulmonary edema, globular heart with whitish areas, petechiae and ecchymosis in the epicardium, myocardium and papillary muscles. Microscopically there was an increase of eosinophilia of cytoplasm of cardiomyocytes, picnosis, cariorrexia, karyolysis, loss of striations and multifocal areas of cardiac fibrosis. In the kidney, there was hydropic vacuolar degeneration and necrosis of epithelial cells in convoluted tubules. The clinical signs presented by the cattle poisoned were similar to those previously described by plants containing MFA. The macroscopic and microscopic lesions described in the heart and kidneys are of great diagnostic value. A. septentrionalis is the main toxic plant of livestock interests in the studied regions due to direct and indirect economic losses in livestock that causes.
\end{abstract}

INDEX TERMS: Poisonous plants, Amorimia septentrionalis, plant poisoning, sudden death, MFA, cardiac fibrosis, cattle.

RESUMO.- Amorimia septentrionalis contém monofluoracetato de sódio e quando consumida por ruminantes provoca morte súbita. Este estudo teve o objetivo de relatar a epidemiologia, os sinais clínicos e patológicos de surtos de morte súbita em bovinos provocadas por Amorimia septen-

\footnotetext{
${ }^{1}$ Recebido em 17 de março de 2014.

Aceito para publicação em 16 de abril de 2014

${ }^{2}$ Programa de Pós-Graduação em Ciência Veterinária, Departamento de Medicina Veterinária, Universidade Federal Rural de Pernambuco (UFRPE). Rua Dom Manoel de Medeiros s/n, Dois Irmãos, Recife, PE 52171-900, Brasil.

${ }^{3}$ Programa de Pós-Graduação em Ciência Animal Tropical, Departamento de Morfologia e Fisiologia Animal (DMFA), Universidade Federal Rural de Pernambuco, Recife, PE 52171-900.
}

trionalis nos Estados de Pernambuco e Paraíba. Para isso, realizaram-se visitas técnicas em diversas propriedades nas Microrregiões do Médio Capibaribe/PE e Itabaiana/PB. Oito bovinos foram necropsiados. Coletaram-se tecidos das cavidades abdominal e torácica, além do encéfalo e medu-

\footnotetext{
${ }^{4}$ Hospital Veterinário, Centro de Saúde e Tecnologia Rural (CSTR), Campos de Patos, Universidade Federal de Campina Grande, Patos, PB 58700000, Brasil.

${ }^{5}$ Poisonous Plant Research Laboratory, Agricultural Research Service, United States Department of Agriculture, 1150 E. 1400 N., Logan, UT 84341, USA.

${ }^{6}$ Laboratório de Diagnóstico Animal, Departamento de Morfologia e Fisiologia Animal, UFRPE, Recife, PE 52171-900. *Autor para correspondência: $\underline{\text { fabio.mendonca@pq.cnpq.br }}$
} 
la espinhal. As alterações clínicas consistiram em lentidão, decúbito esternal prolongado, relutância em se movimentar quando em estação, cansaço, taquipneia, taquicardia e pulso venoso positivo. Os bovinos que foram forçados a se movimentar apresentaram instabilidade, tremores musculares e queda repentina seguida de vocalizações, movimentos de pedalagem e morte súbita em cerca de 5 a 7 minutos. As principais alterações macroscópicas consistiram em edema pulmonar, coração com aspecto globular com áreas esbranquiçadas, petéquias e equimoses no epicárdio, miocárdio e músculos papilares. À microscopia observou-se aumento da eosinofilia do citoplasma dos cardiomiócitos, núcleos picnóticos, cariorrexia, cariólise, perda das estriações, edema intersticial, infiltrado inflamatório intersticial mononuclear e áreas multifocais de fibrose cardíaca. Nos rins, constatou-se degeneração hidrópico vacuolar e necrose das células epiteliais em túbulos contorcidos. Os sinais clínicos foram semelhantes aos sinais clínicos já descritos em bovinos por plantas que contém MFA. As lesões macro e microscópicas descritas no coração e rins são de grande valor diagnóstico. A. septentrionalis é a principal planta tóxica de interesse pecuário nas microrregiões do Médio Capibaribe e Itabaiana devido às perdas econômicas diretas e indiretas que provoca na pecuária dessas regiões.

TERMOS DE INDEXAÇÃO: Plantas tóxicas, Amorimia septentrionalis, intoxicação por planta, morte súbita, MFA, fibrose cardíaca, bovinos.

\section{INTRODUÇÃO}

As plantas que causam morte súbita associada ao exercício estão dentre as mais importantes plantas tóxicas para ruminantes no Brasil (Tokarnia et al. 2012, Duarte et al. 2013b). Fazem parte desse grupo, plantas das famílias Rubiaceae, Bignoniaceae e Malpighiaceae. No nordeste do Brasil são importantes as intoxicações por Palicourea marcgravii e Palicoureia aeneofusca. Essas rubiaceas ocorrem apenas em regiões de mata atlântica no litoral e zona da mata nordestina ou ocorrem de forma mais restrita em áreas de brejo de altitude no agreste dos Estados de Pernambuco e Paraíba. As espécies de Amorimia, anteriormente classificadas como Mascagnia (Anderson 2006), são encontradas em todas as regiões do Brasil (Mamede 2010) e no nordeste do país causam surtos de intoxicação em praticamente toda região semiárida (Riet-Correa et al. 2011).

No semiárido nordestino são importantes as intoxicações por A. rigida e A. septentrionalis. A. rigida é a Malpighiaceae mais conhecida, difundida e importante de toda a região nordeste do país (Duarte et al. 2013b). Têm provocado surtos de intoxicações principalmente em bovinos (Medeiros et al. 2002, Silva et al. 2006, Vasconcelos et al. 2008b) e menos freqüentemente em caprinos (Oliveira et al. 1978) e ovinos (Pacífico da Silva et al. 2008, Lago et al. 2009).

A. septentrionalis ocorre especialmente nos Estados do Ceará, Paraíba e Pernambuco (Mamede 2010) e surtos de intoxicação por essa planta foram descritos em ovinos e caprinos no estado da Paraíba (Vasconcelos et al. 2008a).

Em ambos os casos, as intoxicações ocorrem principalmente no início do período chuvoso, quando essas plantas brotam antes de outras forrageiras ou após o final desse período, quando algumas forrageiras secam (Vasconcelos et al. 2008a, Borboleta 2010, Tokarnia et al. 2012).

Na maior parte dos surtos de intoxicação por Amorimia spp. reportados no Brasil, não são descritas alterações significativas à necropsia e a lesão microscópica mais frequente é a degeneração hidrópica vacuolar nas células epiteliais dos túbulos renais (Tokarnia et al. 2012), no entanto, também têm sido descritos casos espontâneos e experimentais de intoxicação em que se observa fibrose cardíaca (Schons et al. 2011, Soares et al. 2011). Este estudo tem o objetivo de relatar a epidemiologia, os sinais clínicos e a patologia de surtos de mortes súbitas associadas com fibrose cardíaca em bovinos nos Estados de Pernambuco e Paraíba.

\section{MATERIAL E MÉTODOS}

Identificação botânica. A identificação botânica foi realizada pelo Dra. Rita de Cássia Araújo Pereira (Herbário do Instituto Agronômico de Pernambuco, Recife, PE, Brasil). Folhas de A. septentrionalis foram enviadas ao Poisonous Plant Laboratory, Agricultural Research Service, United States Department of Agriculture, Logan, UT, USA, para verificação da existência de MFA em sua composição, conforme metodologia descrita por Lee et al. (2012).

Investigação epidemiológica, sinais clínicos e patologia. Realizaram-se visitas técnicas a diversas propriedades dos $\mathrm{Mu}$ nicípios de Passira e Limoeiro na Microrregião do Médio Capibaribe, PE, e Salgado de São Félix e Itabaiana na Microrregião de Itabaiana, PB. As visitas foram realizadas entre junho de 2011 e junho 2013 com a finalidade de coletar informações referentes aos surtos de mortes súbitas em bovinos, mediante a realização de entrevistas com médicos veterinários, com os responsáveis pelas criações e vistoria das pastagens onde a doença ocorria. Para as entrevistas foi utilizado um formulário similar ao utilizado por Silva et al. 2006, com espaço para identificação do entrevistado e perguntas sobre a ocorrência de plantas tóxicas e surtos na região estudada. 0 clima predominante nos Municípios que compreendem essa microrregião é o semiárido, com temperaturas elevadas e chuvas escassas e mal distribuídas. A vegetação característica é a caatinga (IBGE 2010).

Três bovinos, de diferentes idades, dois machos e uma fêmea, naturalmente intoxicados por $A$. septentrionalis foram examinados mais detalhadamente e necropsiados após sua morte. Outros cinco bovinos que haviam morrido ao serem movimentados pelos produtores rurais foram necropsiados pelos veterinários das fazendas que enviaram amostras de tecidos ao Laboratório de Diagnóstico Animal da Universidade Federal Rural de Pernambuco (LDA/UFRPE) para exame histopatológico. Coletaram-se tecidos das cavidades abdominal e torácica, além do encéfalo e medula espinhal. Após fixação em solução de formalina a 10\%, as amostras foram seccionadas em cortes transversais de 4-5 mm. Esses fragmentos foram processados de acordo com os métodos de rotina, corados pela hematoxina-eosina e avaliados histopatologicamente. Amostras de tecido cardíaco foram também coradas pelo tricrômico de Gomori.

\section{RESULTADOS}

A planta foi identificada como Amorimia septentrionalis W.R. Anderson (Fig.1 e 2) e nas amostras coletadas em abril de 2013, detectou-se $0,0021 \%$ de MFA nas folhas da planta adulta.

Em Pernambuco, históricos de mortes súbitas após a movimentação de bovinos foram obtidos principalmente 

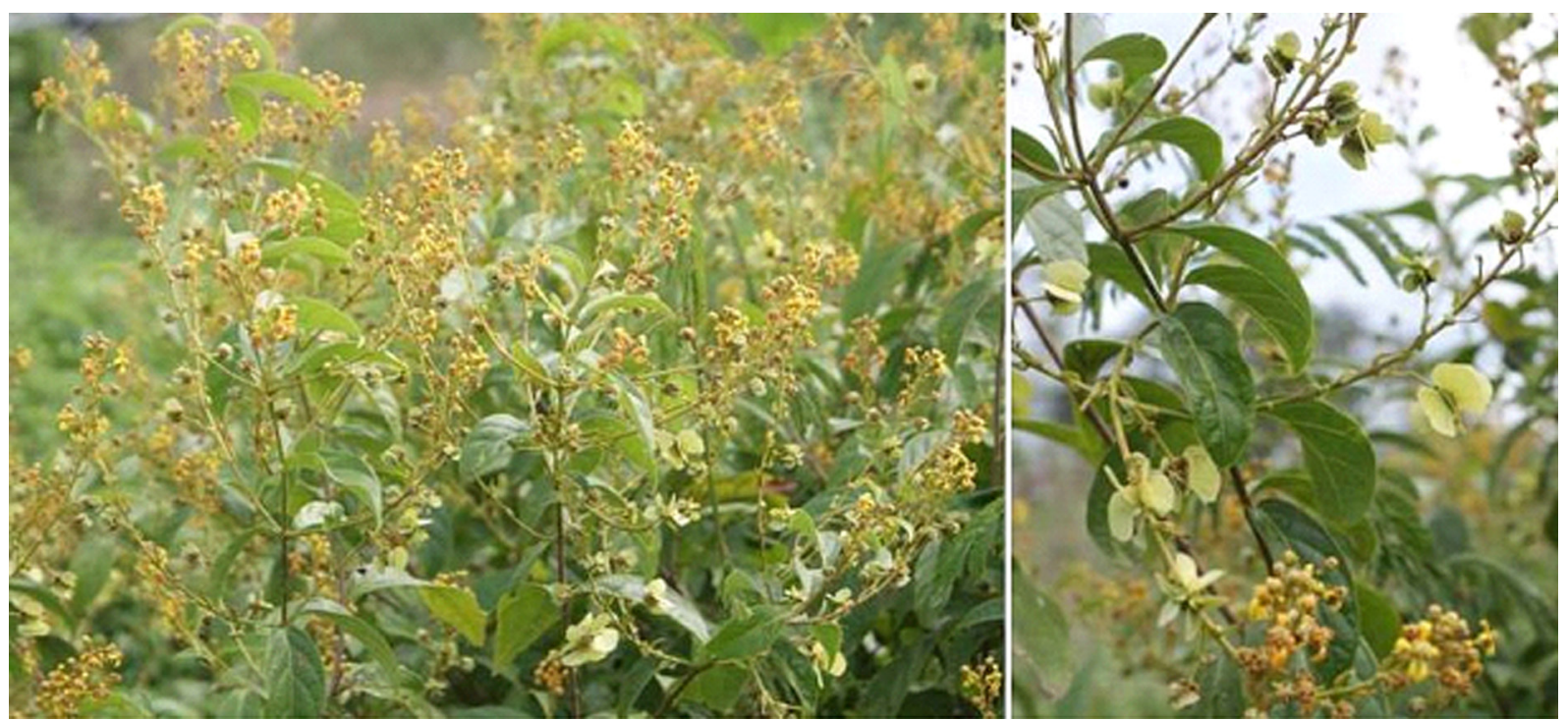

Fig.1. Amorimia septentrionalis em floração e frutificação. Maio de 2013, município de Passira, PE.

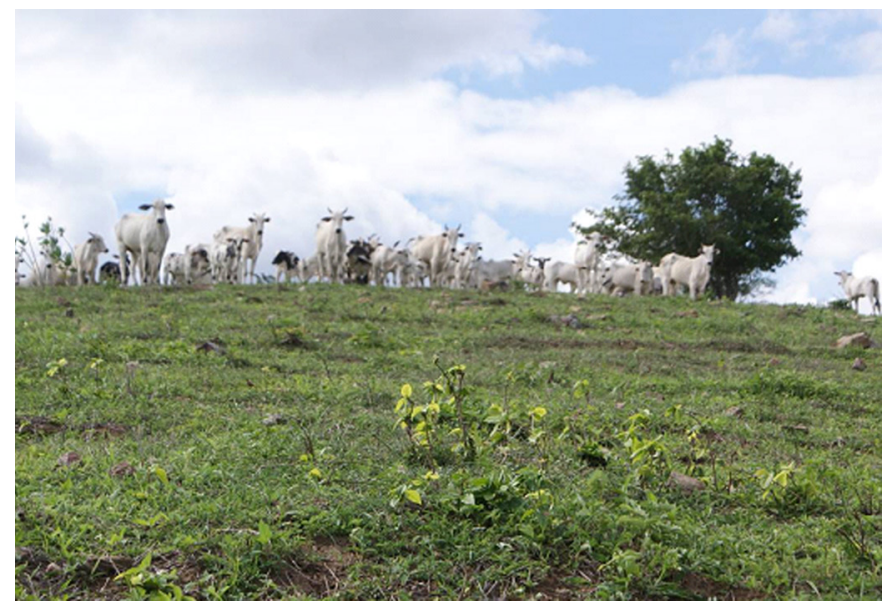

Fig.2. Área de pastagem invadida por Amorimia septentrionalis em fase de brotação. Maio de 2013, município de Passira, PE.

após o início do período chuvoso, que se estende de abril a junho. A Microrregião do Médio Capibaribe está inserida na área de abrangência do polígono das secas, porém, apresenta um período de estiagem menor que a do sertão devido a proximidade com o litoral. Os índices pluviométricos não ultrapassam $295 \mathrm{~mm}$ na estação chuvosa e 25 $\mathrm{mm}$ na estação seca. Na Paraíba, os históricos de intoxicação também se concentram no período chuvoso. Porém, casos esporádicos de morte súbita associados ao exercício ocorrem durante todo o ano. A microrregião de Itabaiana está incluída na área geográfica de abrangência do semiárido brasileiro. A vegetação é basicamente composta por caatinga hiperxerófila com trechos de floresta caducifólia. 0 clima é do tipo tropical semiárido, com chuvas de verão e o período chuvoso se inicia em novembro com término em abril. A precipitação média anual é de 431,8mm (IBGE 2010).

Dois surtos foram acompanhados no Município de Passira/PE em propriedades com média de 100 hectares onde se criavam bovinos mestiços da raça nelore. 0 manejo adotado era o semi-extensivo e a pastagem em ambas as propriedades era formada principalmente por Buffel grass (Cenchrus ciliaris) e Brachiaria decumbens. Na propriedade A, de um lote de 50 animais, morreram 14 no mês de abril de 2011. Casos de mortes súbitas de bovinos nessa propriedade continuaram a ocorrer nos meses de abril a maio de 2012 e 2013 (oito bovinos adultos no total). Na propriedade B, eram criados 180 bovinos, sendo que as mortes foram observadas principalmente num lote de animais trazido há cerca de 30 dias do sertão do Estado de Pernambuco, a uma distância de $240 \mathrm{~km}$. Nessa propriedade, adoeceram e morreram 27 bovinos.

$\mathrm{Na}$ Propriedade C, localizada em Limoeiro/PE, havia um rebanho de 11 bovinos criados numa área de 3,0 ha, onde recentemente implantou-se Brachiaria decumbens em seguida a um período de estiagem que causou pouca disponibilidade de pasto e os bovinos passaram a consumir A. septentrionalis; durante a inspeção da pastagem observaram-se vários espécimes da planta com sinais de terem sido consumidos. Cinco bovinos adultos, machos, morreram de forma súbita após terem permanecido por cerca de 30 dias nessa área. Após esses eventos, tentou-se a retirada dos animais para outra fazenda. Durante o manejo, outros dois bovinos morreram de forma súbita.

Em outras duas fazendas em Salgado de São Félix/PB, (Propriedades D e E), morreram de forma súbita, em abril de 2013, 12 bovinos de um total de 37 animais que eram criados de forma semi-extensiva numa área nativa de pastejo, com aproximadamente 50 ha. Nessas propriedades, mortes súbitas de bovinos têm sido detectadas há vários anos e apesar dos produtores rurais conhecerem A. septentrionalis; casos de intoxicação continuam a ocorrer porque a planta é difícil de ser erradicada das pastagens.

Os sinais clínicos da intoxicação por A. septentrionalis, nos três bovinos examinados, foram similares e consistiram principalmente em lentidão, maior tempo em decúbito esternal, relutância em se movimentar ou se levantar, cansaço, taquipneia, taquicardia e pulso venoso positivo. 

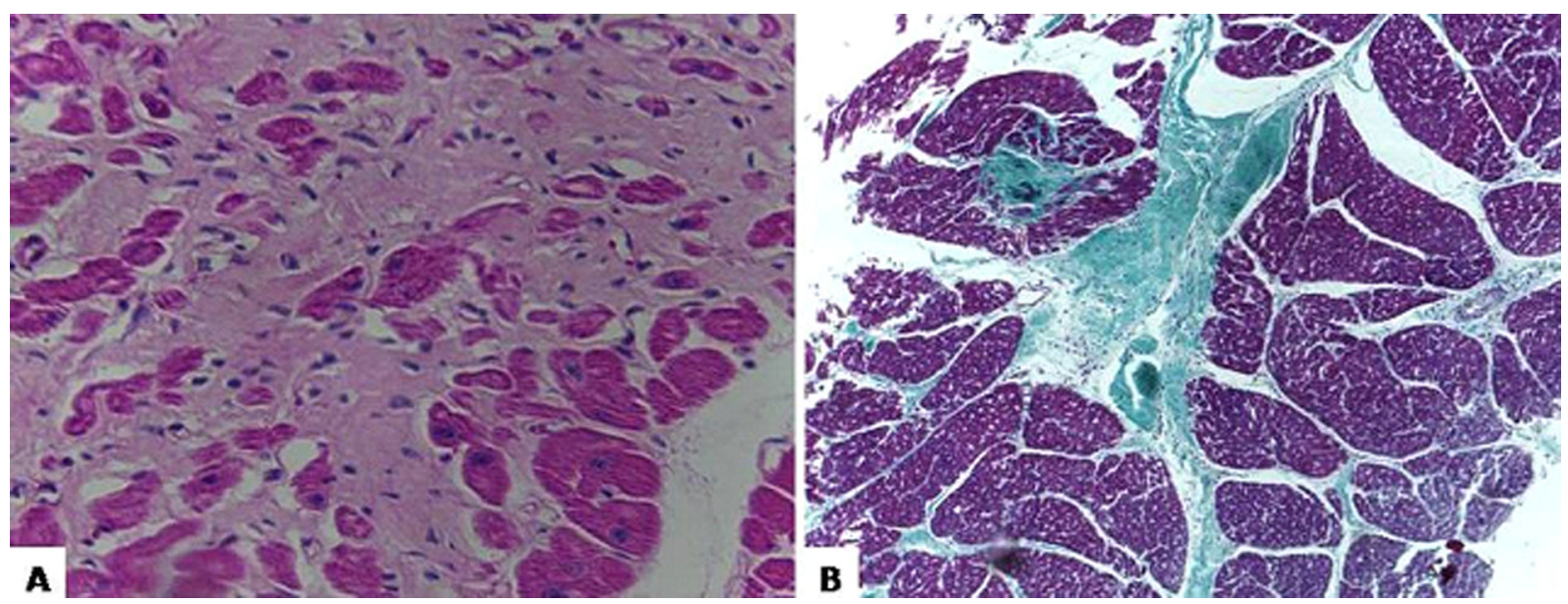

Fig.3. Intoxicação por A. septentrionalis em bovino. (A) Necrose de coagulação no miocárdio, aumento da eosinofilia do citoplasma dos cardiomiócitos, núcleos picnóticos, cariorrexia, cariólise e perda das estriações e fibrose. HE, obj.10x. (B) Áreas multifocais de fibrose cardíaca. Tricrômico de Gomori, obj.4x.

Os animais que foram forçados a se movimentar apresentaram instabilidade, tremores musculares e uma única queda seguida de vocalizações, movimentos de pedalagem e morte em cerca de 5 a 7 minutos.

Ao exame macroscópico, em dois bovinos, não foram observadas lesões significativas. 0 terceiro bovino apresentava edema pulmonar e o coração com aspecto globular com áreas esbranquiçadas, petéquias e equimoses no epicárdio, miocárdio e músculos papilares. Nesse bovino, havia necrose de coagulação no miocárdio com aumento da eosinofilia do citoplasma dos cardiomiócitos, núcleos picnóticos, cariorrexia e cariólise, além de perda das estriações. Havia também edema intersticial, infiltrado inflamatório intersticial mononuclear e áreas multifocais de fibrose cardíaca (Fig.3); essas lesões também foram observadas em duas amostras recebidas no LDA/UFRPE. Nos outros bovinos não foram observadas lesões significativas. Nos rins de cinco bovinos examinados histologicamente também havia degeneração hidrópico vacuolar e necrose das células epiteliais dos túbulos contorcidos.

\section{DISCUSSÃO}

Amorimia septentrionalis é a principal planta tóxica de interesse pecuário nas microrregiões do Médio Capibaribe e Itabaiana devido às perdas econômicas diretas e indiretas que provoca para a pecuária local. A planta apresenta um sistema radicular muito desenvolvido o que facilita sua propagação nas pastagens do semiárido nordestino. 0 uso de cercas para isolar as áreas com a planta não é uma medida de controle usada nas propriedades visitadas. Esse fator facilita a ocorrência de intoxicações, pois o tipo de manejo adotado na maioria das propriedades é semi-extensivo; os bovinos são soltos para pastar em áreas extensas de caatinga e quando são recolhidos apresentam o quadro de intoxicação aguda. Preventivamente recomenda-se parar a movimentação de bovinos quando se nota o início do quadro clínico, deixando-os em repouso por um período de 7 a 15 dias.

No semiárido nordestino, a intoxicação por A septentrionalis havia sido descrita em ovinos e caprinos no estado da Paraíba, onde inicialmente a planta foi classificada como A. rigida (Vasconcelos et al., 2008a). Nesses casos, a concentração de MFA em amostras das folhas da planta era similar (cerca de 0,002 $\pm 0,0009 \%$ ) ao deste estudo. Porém, variações na toxicidade da planta podem ocorrer e devem ser levadas em consideração na patogenia da intoxicação (Tokarnia et al. 1994, Medeiros et al. 2002).

Os sinais clínicos apresentados foram semelhantes aos sinais clínicos já descritos em bovinos intoxicados por plantas que contém MFA (Lee et al. 2012, Tokarnia et al. 2012). Macroscopicamente, as únicas lesões com significado foram o edema pulmonar e o coração de aspecto globoso. Essas alterações se devem à insuficiência cardíaca. $\mathrm{Na}$ microscopia, as lesões cardíacas consistiram em infiltrado inflamatório intersticial mononuclear e áreas multifocais de fibrose. Até o momento, esses achados foram descritos apenas na intoxicação espontânea por A. exotropica em bovinos (Soares et al. 2011), na intoxicação experimental por A. exotropica em coelhos (Soares et al. 2011) e por uma espécie erroneamente identificada como $A$. sepium, possivelmente tratando-se de Amorimia amazônica, em ovinos (Schons et al. 2011, Lee et al. 2012). Fibrose cardíaca também pode ser observada em ovinos intoxicados experimentalmente pelo MFA (Schultz et al. 1982).

Provavelmente a fibrose do miocárdio causada por Amorimia spp. em bovinos deve-se ao seu consumo em pequenas quantidades e por mais de 40 dias (Soares et al, 2011). No Brasil, nas intoxicações por outras plantas que contêm MFA não se tem descrito fibrose cardíaca. No caso de Palicourea spp., a ausência de fibrose cardíaca pode ser devida ao fato de que as plantas deste gênero contem maiores concentrações de MFA do que Amorimia spp. (Lee et al. 2012, Cook et al. 2014) e dificilmente animais ingerindo Palicourea spp. poderão ingerir doses baixas repetidas de MFA. Assim como nas demais plantas que causam morte súbita, nas intoxicações por Amorimia spp. em ruminantes deve-se levar em consideração a lesão microscópica dos rins, pois quando presente, é de grande valor diagnóstico (Tokarnia et al. 2012).

No Brasil, causas de fibrose cardíaca em bovinos incluem as intoxicações por Tetrapterys spp. e Ateleia glazio- 
viana (Gava et al. 2001, Peixoto et al. 1995, Tokarnia et al. 1989, 2012). Porém essas plantas não ocorrem na região estudada. A intoxicação por Senna obtusifolia também dever ser levada em consideração no diagnóstico diferencial da doença, pois existem casos descritos em que os principais achados foram vacuolização de células musculares cardíacas e fibrose focal (McCormack \& Neisler 1980). Outras causas de fibrose cardíaca em bovinos incluem intoxicações acidentais por antibióticos ionóforos (Radostits et al. 2007) e a distrofia muscular causada deficiência de vitamina E/selênio. Porém, nessas doenças os músculos esqueléticos são também afetados (Barros et al. 1988).

0 controle da intoxicação por $A$. septentrionalis em bovinos é difícil. A remoção manual da planta é uma boa medida de controle para pequenas áreas, porém esse procedimento não é viável em áreas onde a planta está difundida (Duarte et al. 2013, 2013b). Outras formas de controle que têm sido experimentalmente testadas incluem a indução de aversão alimentar condicionada, a administração de doses não tóxicas da planta para induzir resistência e a administração intra-ruminal de bactérias aeróbicas que degradam o MFA (Camboim et al. 2012a, 2012b, Duarte 2013a). Porém, essas técnicas ainda não foram testadas em condições de campo.

\section{REFERÊNCIAS}

Anderson W.R. 2006. Eight segregates from the neotropical genus Mascagnia (Malpighiaceae). Novon. 16:168-204.

Borboleta L.R. 2010. Intoxicação experimental com extratos de Mascagnia rigida (A. Juss.) Griseb. (Malpighiaceae) em coelhos (Oryctolagus cuniculus): estudos clínico, laboratorial e anatomopatológico. Dissertação (Mestrado em ciência animal). Curso de Pós-graduação em Ciência Animal, Universidade Federal de Minas Gerais, Belo Horizonte. 143f.

Camboim E.K.A., Tadra-Sfeir M.Z., Souza E.M., Pedrosa F.O., Andrade P.P., McSweeney C.S., Riet-Correa F. \& Melo M.A. 2012a. Defluorination of sodium fluoroacetate by bacteria from soil and plants in Brazil. The Scientific. World Journal. Article ID 149893. 5p.

Camboim E.K.A., Almeida A.P., Tadra-Sfeir M.Z., Junior F.G., Andrade P.P., McSweeney C.S., Melo M.A. \& Riet-Correa F. 2012b. Isolation and identification of sodium fluoroacetate degrading bacteria from caprine rumen in Brazil. The Scientific World Journal, Article ID 178254. 6p.

Cook D., Lee S.T., Taylor C.M., Bassüner B., Riet-Correa F., Pfister J.A. \& Gardner D.R. 2014. Detection of toxic monofluoroacetate in Palicourea species. Toxicon 80:9-16.

Duarte A.L. L., Medeiros R.M.T., Carvalho F.K.L., Lee S.T., Cook D., Pfister J.A., Costa V.M.M. \& Riet-Corrêa F. 2013a. Induction and transfer of resistance to poisoning by Amorimia (Mascagnia) septentrionalis in goats. J. Appl. Toxicol. 34(2):220-223.

Duarte A.L., Medeiros R.M.T. \& Riet-Correa F. 2013b. Intoxicação por Amorimia spp. em ruminantes. Ciência Rural 43(7):1294-1301.

Gava A., Barros C.S.L., Pilati C., Barros S.S. \& Mori A.M. 2001. Intoxicação por Ateleia glazioviana (Leg. Papilionoideae) em bovinos. Pesq. Vet. Bras. 21(2):49-59.

IBGE 2010. Fundação Instituto Brasileiro de Geografia e Estatística. Acessado em 3 jan. 2014. Disponível em <http://cidades.ibge.gov.br/xtras/ home.php>
Lago E.P., Melo M.M., Araújo R.B., Nascimento E.F., Silva E.F. \& Melo M.B. 2009. Perfis eletrocardiográfico e ecodopplercardiográfico de ovinos após ingestão da suspensão aquosa de Mascagnia rigida Griseb. (Malpighiaceae). Arq. Bras. Med. Vet. Zootec. 61(4):853-862.

Lee S.T., Cook D., Riet-Correa F., Pfister J.A., Anderson W.R., Lima F.G. \& Gardner D.R. 2012. Detection of monofluoroacetate in Palicourea and Amorimia species. Toxicon 60:791-796.

Mamede M.C.H. 2010. Amorimia in Lista de Espécies da Flora do Brasil. Jardim Botânico do Rio de Janeiro. Acessado em 22 dez. 2013. Disponível em <http://floradobrasil.jbrj.gov.br/2010/FB101439>

McCormack J.E. \& Neisler W.E. 1980. Cassia obtusifolia (sicklepod) toxicity in a dairy herd. Vet. Med., Small Anim. Clin. 75:1849-1851.

Medeiros R.M.T., Neto S.A.G., Barbosa R.C., Lima E.F. \& Riet-Correa F. 2002. Sudden bovine death from Mascagnia rigida in Northeastern Brazil. Vet. Hum. Toxicol. 44(5):286-288.

Oliveira A.C., Oliveira G.C., Paraguassu A.A. \& Freire L.M.G.M. 1978. Intoxicação por um "tingui" (Mascagnia rigida Griseb.) em caprinos na Bahia. Anais XVI Cong. Bras. Med. Vet., Salvador, BA, Vol.1, p.172.

Pacífico da Sijva I., Lira R.A., Barbosa R.R., Batista J.S. \& Soto-Blanco B. 2008. Intoxicação natural pelas folhas de Mascagnia rigida (Malpighiaceae) em ovinos. Arqs Inst. Biológico, São Paulo, 75(2):229-233.

Peixoto P.V., Loretti A.P. \& Tokarnia C.H. 1995. Doença do peito inchado, Tetrapterys spp poisoning, brisket disease and St. George disease: a comparative study. Pesq. Vet. Bras. 15:43-50.

Radostits O.M., Gay C.C., Hinchcliff K.W. \& Constable P.D. 2007. Veterinary medicine: a textbook of the diseases of cattle, horses, sheep, pigs, and goats. $10^{\text {th }}$ ed. W.B. Saunders, Philadelphia, p.1797-1849.

Riet-Correa F., Bezerra C.W.C. \& Medeiros R.M.T. 2011. Plantas Tóxicas do Nordeste. Hospital Veterinário, CSTR, Universidade Federal de Campina Grande, Sociedade Vicente Pallotti Editora, Patos, PB, 78p.

Schons S.V., Mello T.L., Riet-Correa F. \& Schild AL. 2011. Poisoning by Amorimia (Mascagnia) septium in sheep in northern Brazil. Toxicon 57:781-786.

Schultz R.A., Coetzer J.A., Kellerman T.S. \& Naudé T.W. 1982. Observations on the clinical, cardiac and histopathological effects of fluoroacetate in sheep. Onderstepoort J. Vet. Res. 49(4):237-245.

Silva D.M., Riet-Correa F., Medeiros R.M.T. \& Oliveira O.F. 2006. Plantas tóxicas para ruminantes e equídeos no Seridó Ocidental e Oriental do Rio Grande do Norte. Pesq. Vet. Bras. 26(4):223-236.

Soares M.P., Pavarini S.P., Adrien M.L., Quevedo P.S., Schild A.L., Peixoto P.V., Farias da Cruz C.S. \& Driemeier D. 2011. Amorimia exotropica poisoning as a presumptive cause of myocardial fibrosis in cattle. J. Vet. Diagn. Invest. 23(6):1223-1229.

Tokarnia C.H., Peixoto P.V., Döbereiner J. \& Consorte L.B. 1989. Tetrapterys spp. (Malpighiaceae), a causa de mortandades em bovinos caracterizadas por alterações cardíacas. Pesq. Vet. Bras. 9:23-44.

Tokarnia C.H., Döbereiner J. \& Peixoto P.V. 1994. Aspectos clínico-patológicos complementares da intoxicação por algumas plantas tóxicas brasileiras. Pesq. Vet. Bras. 14(4):111-121.

Tokarnia C.H., Brito M.F., Barbosa J.D., Peixoto P.V. \& Döbereiner J. 2012. Plantas Tóxicas do Brasil. Editora Helianthus, Rio de Janeiro. 566p.

Vasconcelos J.S., Riet-Correa F., Dantas A.F.M., Medeiros R.M.T., Galiza G.J.N., Oliveira D.M. \& Pessoa A.F.A. 2008a. Intoxicação por Mascagnia rigida (Malpighiaceae) em ovinos e caprinos. Pesq. Vet. Bras. 28(10):521-526.

Vasconcelos J.S., Riet-Correa F., Dantas A.F.M., Medeiros R.M.T. \& Dantas A.J.A. 2008b. Mortes súbitas em bovinos causadas por Palicourea aeneofusca (Rubiaceae) e Mascagnia rigida (Malpighiaceae) na Zona da Mata Paraibana. Pesq. Vet. Bras. 28(10):457-460. 